\title{
Application of Composite Materials in Sports Optics
}

Radim Kupčák, Jan Zouhar

Faculty of Mechanical Engineering, Brno University of Technology, Technická 2896/2 616 69, Brno, Czech Republic,E-mail: 170299@vutbr.cz, zouhar@fme.vutbr.cz

CFRP (Carbon Fiber Reinforced Polymers) are often used when designing parts that need to be stiff, light and thermally stable. These benefits are a big motivation to use CFRP in many applications, one of them could be sports optics. However, optical devices require precise dimensions with tight tolerances for the optical assembly to work correctly. In order to determine if CFRP could be a suitable material of choice for sports optics a simplified body of binoculars was designed. The tubular body was manufactured by prepreg lay-up into a 3D printed mold, followed by curing in an autoclave. After the prototype was manufactured 3D measurements of the tube using 3D scanner GOM ATOS were made. As expected, shrinkage of the mold and the epoxy resin in the matrix of CFRP caused minor deformations. However, if the shape of the cured part remains unchanged during conditions similar to the general use of binoculars, then the initial deformations happening during manufacturing could be accounted for when designing the part.

Keywords: Carbon Fiber, Sports Optic, Prepreg, Composite Materials, 3D scan

\section{Introduction}

Composite materials, specifically CFRP (Carbon Fiber Reinforced Polymers) have recently become more and more accessible as a structural material. They have become so wide-spread because of new technologies that make manufacturing and use of CFRP cheaper and more convenient. These new technologies often offer high levels of automation and short production times. This allows for use of composite materials in mass production industry segments such as lower-end vehicles production, which has not been the case earlier. That can lead to significant weight reductions, which could compensate for the battery weight in electric vehicles, making their overall weight more reasonable. [1]

On the other hand, there are many composite manufacturing technologies based on hand lay-up. Although they might seem out-dated, they are well suited for manufacturing of larger-scale parts or small-series production in general.

CFRP is used in many branches of engineering including consumer goods and sports equipment with the main benefits being weight savings and rigidity. It may come as a surprise, that in sports optics composite materials have not found a use yet. But compared to firearms for example, (where carbon fiber is sometimes used to make tailstocks or handguards), sports optics devices require different kinds of precision - in some cases tolerances in microns.

Carbon fiber composite has density of around 1,7 $\mathrm{kg} / \mathrm{m}^{3}$, which is similar value to magnesium alloys and lower compared to aluminum alloys $\left(2,7 \mathrm{~kg} / \mathrm{m}^{3}\right.$ for 6061). However, CFRP has much higher strength. [2] A comparison of composite materials and metals is not straight forward because of many variables in design of composites. Because of that it is not possible to predict potential weight-savings of CFRP binoculars. It would be affected by the number of layers, their direction and type of fibers and matrix used. These parameters would have to be carefully chosen and then tested on a prototype piece.

This paper has been made in cooperation with Czech manufacturer of optical devices (including sports optics), Meopta - optics, Ltd. In Meopta carbon fiber has been used as structural material in many applications, but sports optics have not been one of them yet. The paper tries to tackle the question, wheater CFRP could be used at all for devices of sports optics and analyses results of chosen manufacturing technology.

Binoculars have been chosen as a model device for the carbon fiber to be used on. A simplified prototype was designed to determine if it would be possible to manufacture binoculars-shaped body out of carbon fiber at all. It lacks a few key features and components of binoculars - for example, optical prisms or focusing mechanism. But it works as an exhibition piece and proof of concept in terms of manufacturing.

The main part of the prototype - carbon fiber tube was 3D scanned with GOM ATOS - optical 3D scanner. The prototype mold used to make the part was scanned as well. The results were compared with the CAD model and the deviations were evaluated. 


\section{Design of the binoculars prototype}

In the beginning, it was necessary to examine the possibilities of manufacturing technologies. Winding is a technology that was considered at first. Because of its nature, it is mostly suitable for parts with circular symmetry. Although it is possible to manufacture more complicated shapes by winding, it often brings many problems. [3] The main advantage of winding is precise control of fiber orientation. It is crucial for parts with high stiffness and strength in one direction. However, for binoculars, all-around durability and resistance to impacts, vibrations and other dynamic loads, is more important. Žmindák [4] analyses the effect of fiber orientation on mechanical properties of composite materials during dynamic loads.

In the end, prepreg lay-up was selected as the manufacturing technology of choice. It is more versatile in terms of attainable shapes and because an autoclave was available it was more cost-effective. Another big argument for using prepreg lay-up is the insert with protrusion, Fig. 1 and Fig. 7. It would be very problematic, if possible at all, to wind carbon fibers around the protrusion. Autoclave curing allows for co-curing the part with the insert, which is very convenient and quite a unique feature of this design. [5]

The binoculars prototype (Fig. 1) consists of two CFRP tubes with 6061 aluminum alloy inserts. These inserts are glued in the tubes and they provide interface for the objective and eyepiece to be mounted. In the middle of the tubes, there is the co-cured polycarbonate insert (3D printed) with a cube-shaped protrusion. The inside structure of the tube can be seen in Fig. 2. The protrusion acts as an interface for the hinge parts to be mounted and glued onto the tubes.

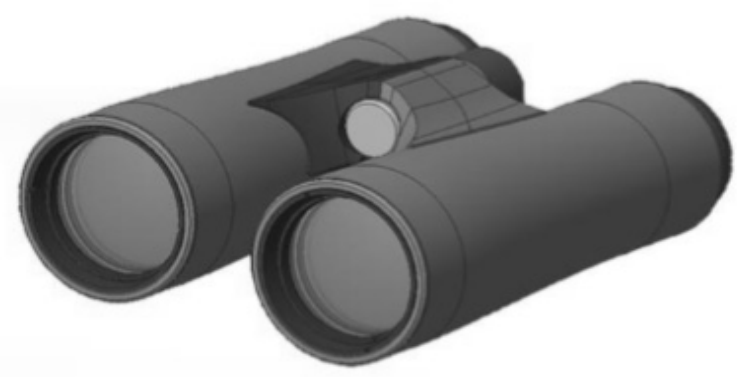

Fig. 1 Binoculars prototype

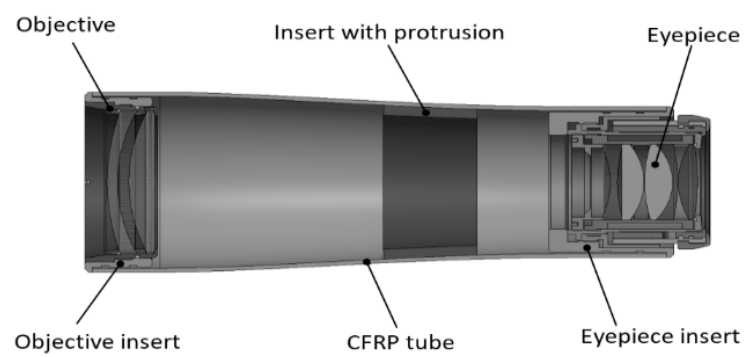

Fig. 2 Structure of the binoculars prototype

\section{Manufacturing of the CFRP tube using prototype mold}

A prototype two-piece negative mold from polycarbonate (PC) was designed to manufacture the tube [6]. The shape of the mold was compensated to account for thermal expansion of the mold that happens at $120^{\circ} \mathrm{C}$ when the epoxy resin is curing.

The volumetric thermal expansion formula was used:

$$
\begin{gathered}
\Delta V=V_{0} \beta \Delta t \\
\beta \approx 3 \alpha
\end{gathered}
$$

Where:

$\Delta \mathrm{V} \ldots$ Change in volume $\left[\mathrm{m}^{3}\right]$,

$\mathrm{V}_{0} \ldots$ Initial volume $\left[\mathrm{m}^{3}\right]$,

$\beta$... Coefficient of volumetric expansion $\left[\mathrm{K}^{-1}\right]$,

$\Delta \mathrm{t} \ldots$ Change in temperature $[\mathrm{K}]$,

$\alpha \ldots$ Coefficient of linear expansion $\left[\mathrm{K}^{-1}\right]$.

The coefficient $a$ of PC is $68,4 \times 10^{-6} \mathrm{~K}^{-1}$ [7]. The mold was $3 \mathrm{D}$ printed out of polycarbonate using professional-grade 3D printer Stratasys Fortus 360 L (Fig. 3). The surface of the mold was hand finished with a fine-grit sandpaper. The alignment of both parts is secured with two centering pins that fit in holes, which were finished with a reamer. General dimensions of the mold can be seen in Fig. 4.

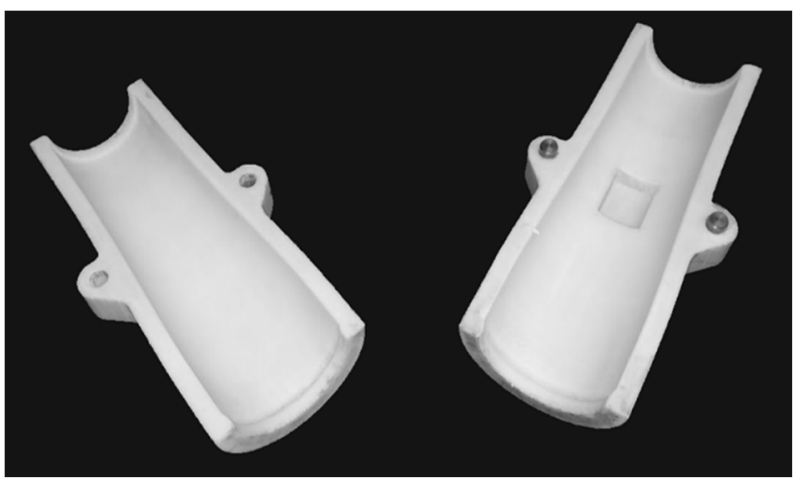

Fig. 3 Two-piece mold

Before lay-up sealant and release-agent were applied to those surfaces of the mold, which will be in contact with prepregs. For the lay-up, four layers of prepregs from Delta Preg have been applied [8] - two sheets of GG380 DT121 and two sheets of GG245 DT121, Table 1. Layers of carbon have been layed up in both halves of the mold to create symmetric and balanced lay-up, Figure 5. Where the two parts of the mold meet, the prepregs were overlapped by $10 \mathrm{~mm}$. Several other lay-up styles were tested in the process. The part was bagged, vacuumed and cured in Maroso automatic autoclave (diameter of the chamber $1 \mathrm{~m}$, length $2 \mathrm{~m}$ ). The heat and pressure cycles are shown in Fig. 6. After manufacturing 10 pieces of tubes, the $3 \mathrm{D}$ printed mold was at the end of its life. 


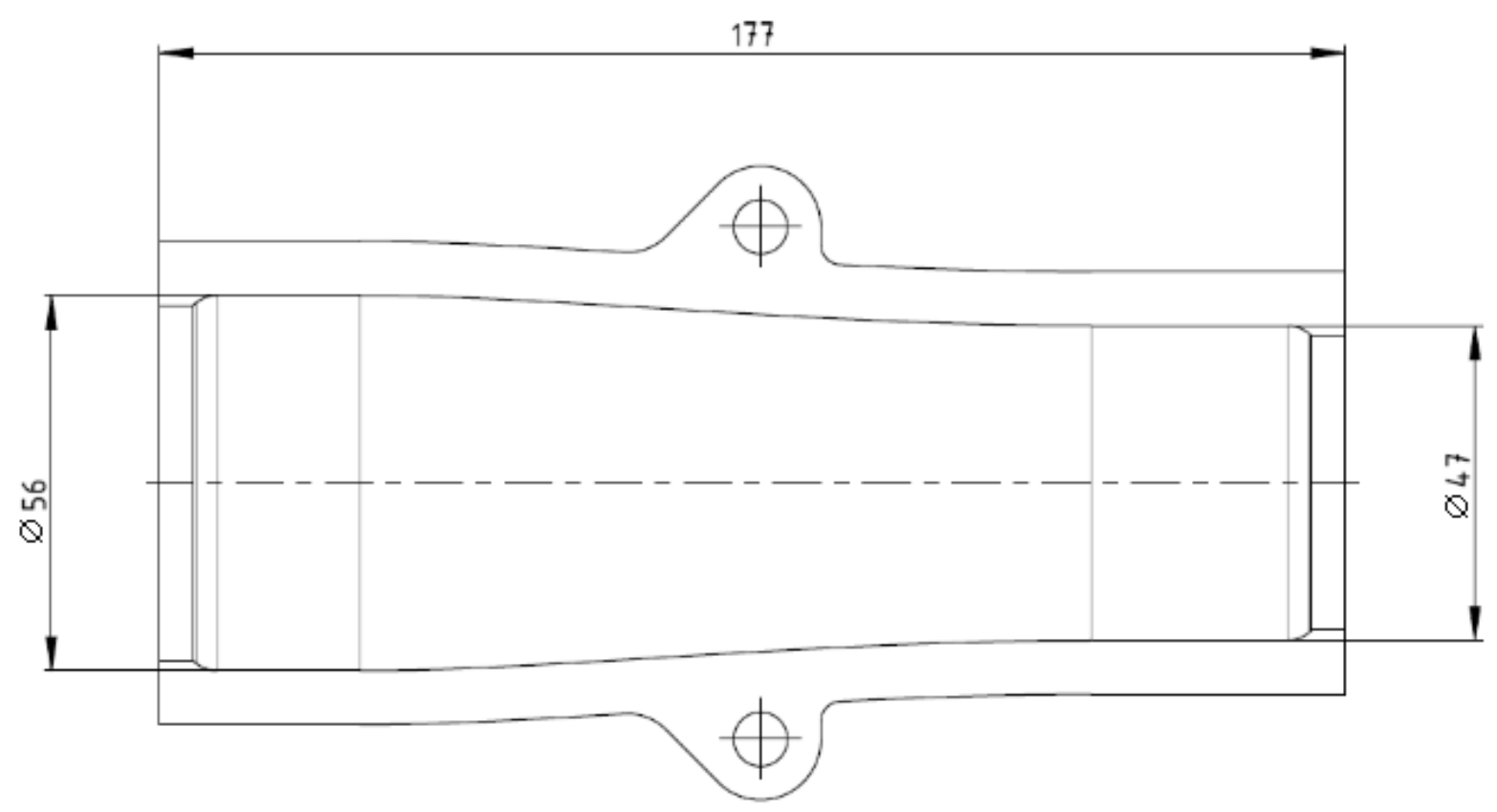

Fig. 4 Mold dimension

Tab. 1 Lay-up scheme

\begin{tabular}{|c|c|}
\hline \multicolumn{2}{|c|}{ Mold } \\
\hline $245 \mathrm{~g} / \mathrm{m}^{2}$ & $\pm 45^{\circ}$ \\
\hline $380 \mathrm{~g} / \mathrm{m}^{2}$ & $0^{\circ}, 90^{\circ}$ \\
\hline $380 \mathrm{~g} / \mathrm{m}^{2}$ & $0^{\circ}, 90^{\circ}$ \\
\hline $245 \mathrm{~g} / \mathrm{m}^{2}$ & $\pm 45^{\circ}$ \\
\hline \multicolumn{2}{|c|}{ Peel Ply } \\
\hline \multicolumn{2}{|c|}{ Separation layer } \\
\hline \multicolumn{2}{|c|}{ Breather cloth } \\
\hline \multicolumn{2}{|c|}{$\overline{\text { Vacuum bag }}$} \\
\hline
\end{tabular}

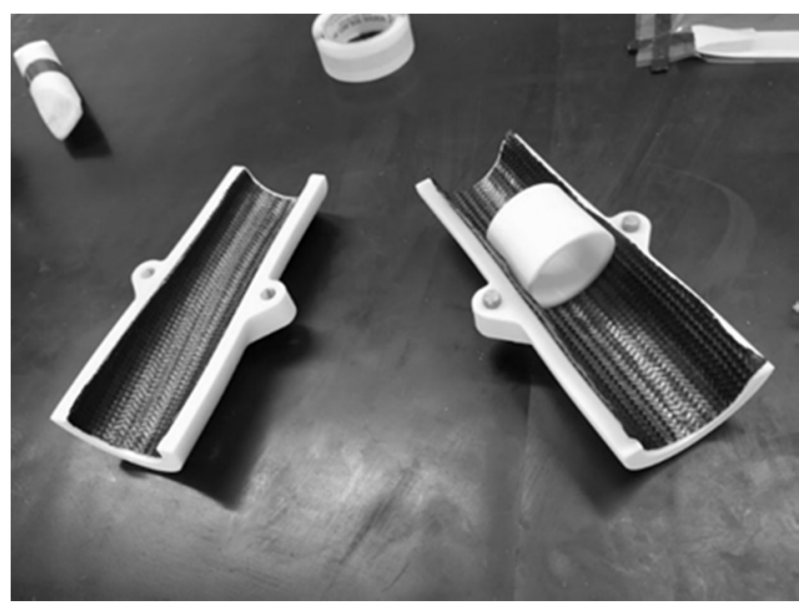

Fig. 5 Process of lay-up

After curing, the tube needed to be finished. Faces of the tube were milled and the remains of parting line were sanded off. Milling composite materials requires special tools with different geometry to tools that are used for machining metals. Because only 10 prototype tubes were made, regular tools have been used. Because of that, tool wear was rapid and the surface finish wasn't satisfactory. The part needed to be handfinished. In production on a greater scale, proper tools and optimized cutting speeds would have to be used. [9]

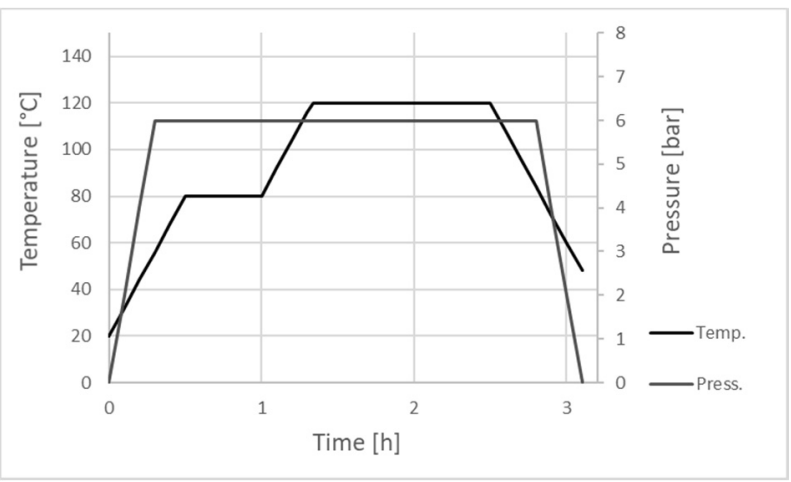

Fig. 6 Autoclave pressure and temperature cycle

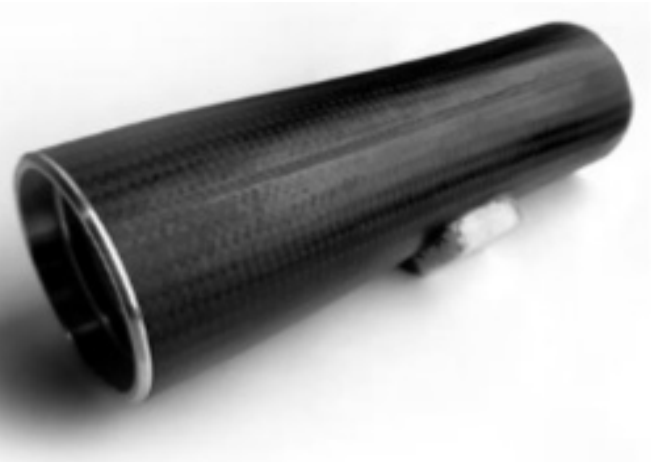

Fig. 7 Finished tube with inserts glued in place 
The last step of the manufacturing process was gluing the threaded inserts (Fig. 7). Because the main purpose of this prototype was being displayed as an exhibition piece, achieving the concentricity of the inserts was not necessary. However, this would be a crucial parameter in real, properly working binoculars. Concentricity could be secured with alignment jig or by turning the inserts after gluing.

\subsection{The process of 3D scanning}

The mold and the carbon fiber tube were measured using an optical 3D scanner GOM ATOS. The parts were sprayed with anti-glare spray. It leaves temporary matt white finish. Self-adhesive reference points were placed on the surface of the part. [10][11].

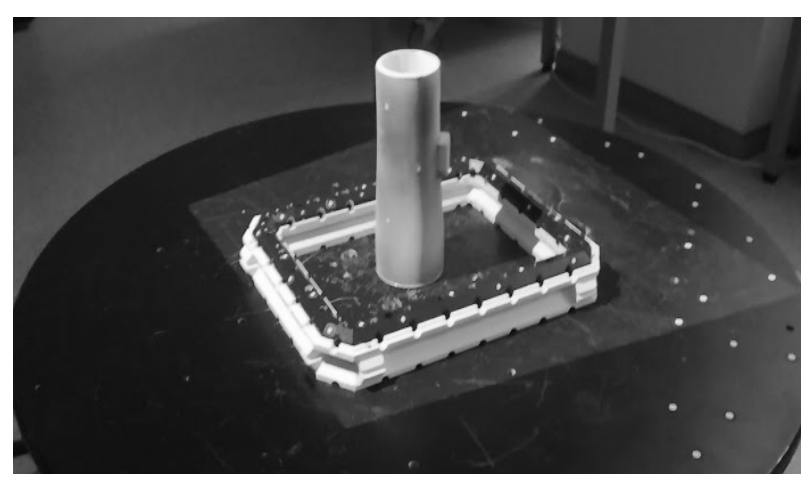

Fig. $83 D$ scanning of the tube
To ensure even scanning, the parts were placed onto a programmed turntable during scanning (Fig. 8 andFig. 9). Result of the measurements was a polygonal mesh that was exported as a STL file.

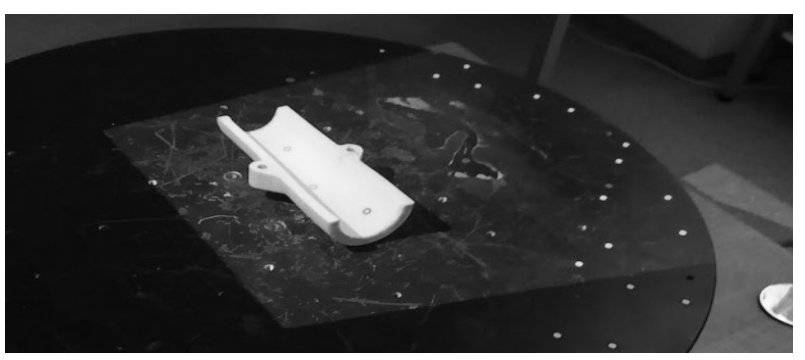

Fig. 93D scanning of the mold

\subsection{Evaluation of data}

The measured data was evaluated using software: GOM Inspect and Microsoft Excel. In GOM Inspect a .STL file was imported. The alignment of the actual data with the CAD model was made with Local Best Fit on the conical part of the tube. According to requirements by Meopta to get a complete topography of the mold, cross-sections with intervals of $10 \mathrm{~mm}$ were created across the part in GOM Inspect. In each cross-section measurements every 5 degrees were taken (Fig. 10). The analyzed mold in the GOM Inspect environment can be seen in Fig. 11, result values discussed in chapter 4.

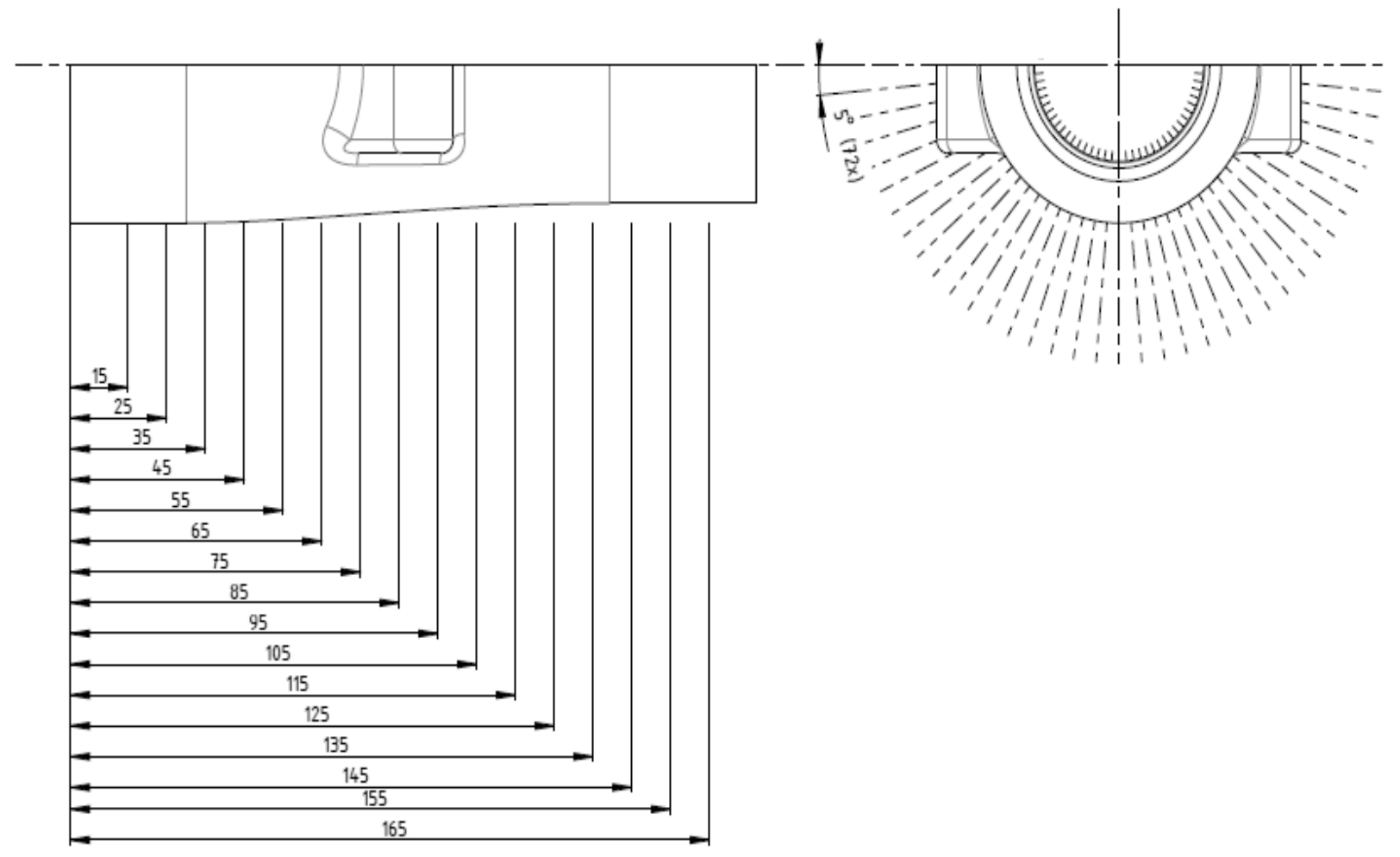

Fig. 10 Measured cross-sections and points of the mold 

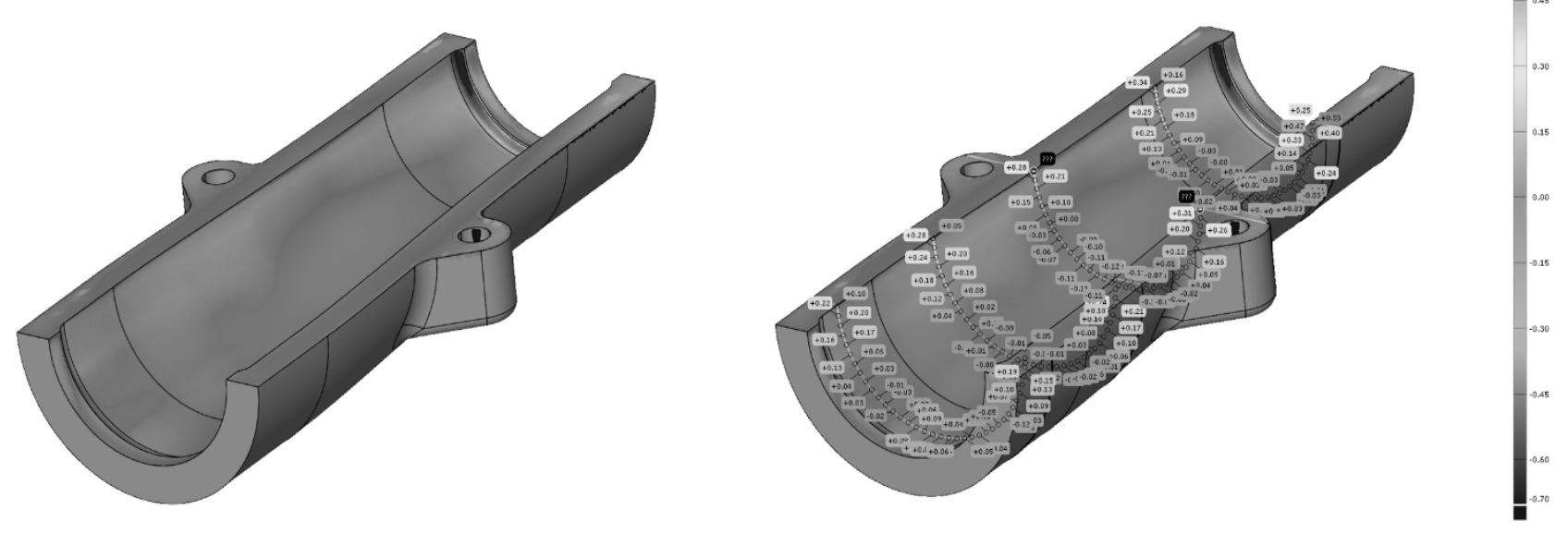

Fig. 11 Difference report mold with $C A D$ model

For the tube, the same method was applied with one difference - the measurements were taken around the full circumference of the cross-sections (Fig. 12).
The cross-sections of the part and the mold align with each other. The tube in the GOM Inspect environment can be seen in Fig. 13.
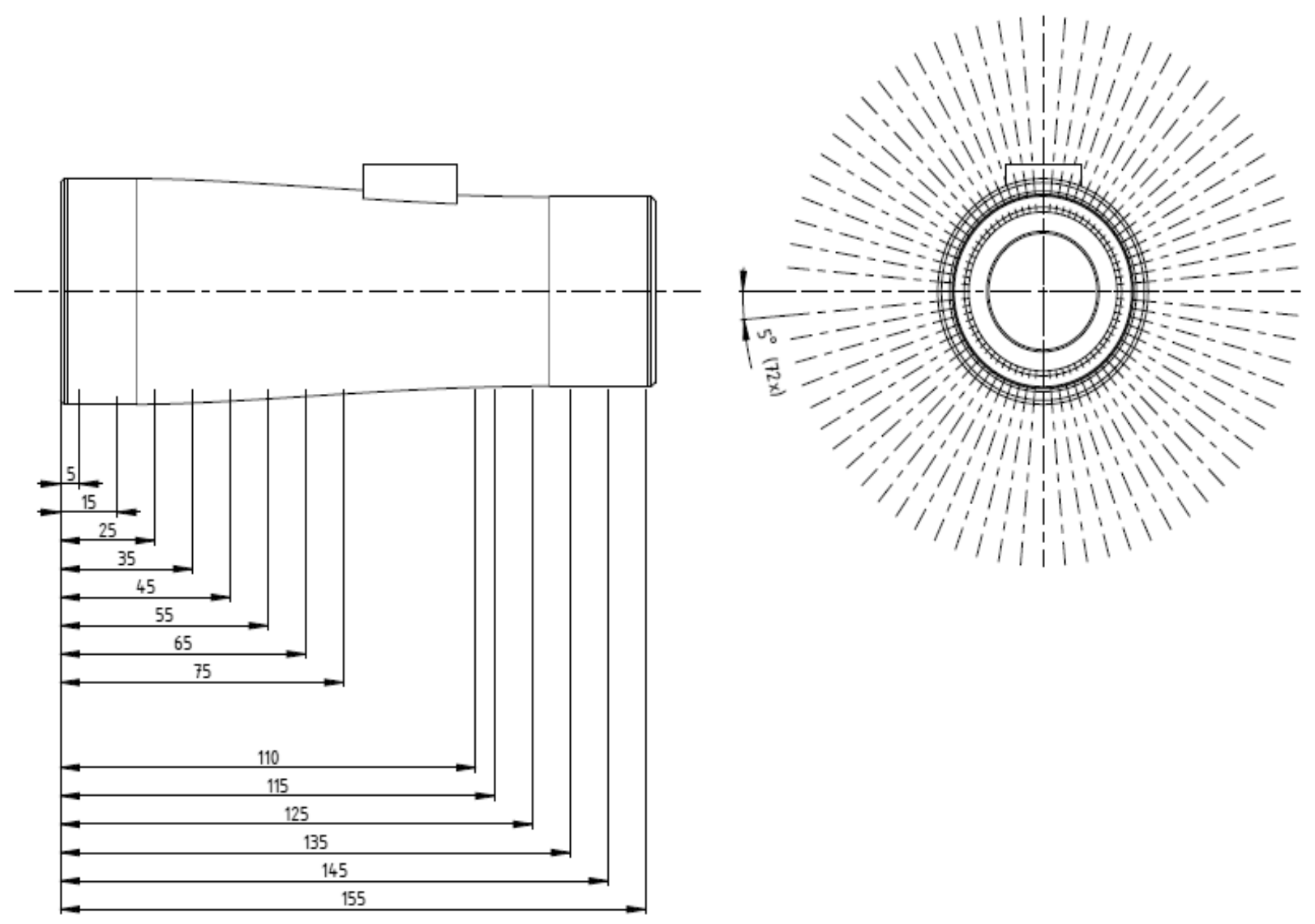

Fig. 12 Measured cross-sections and points of the tube 

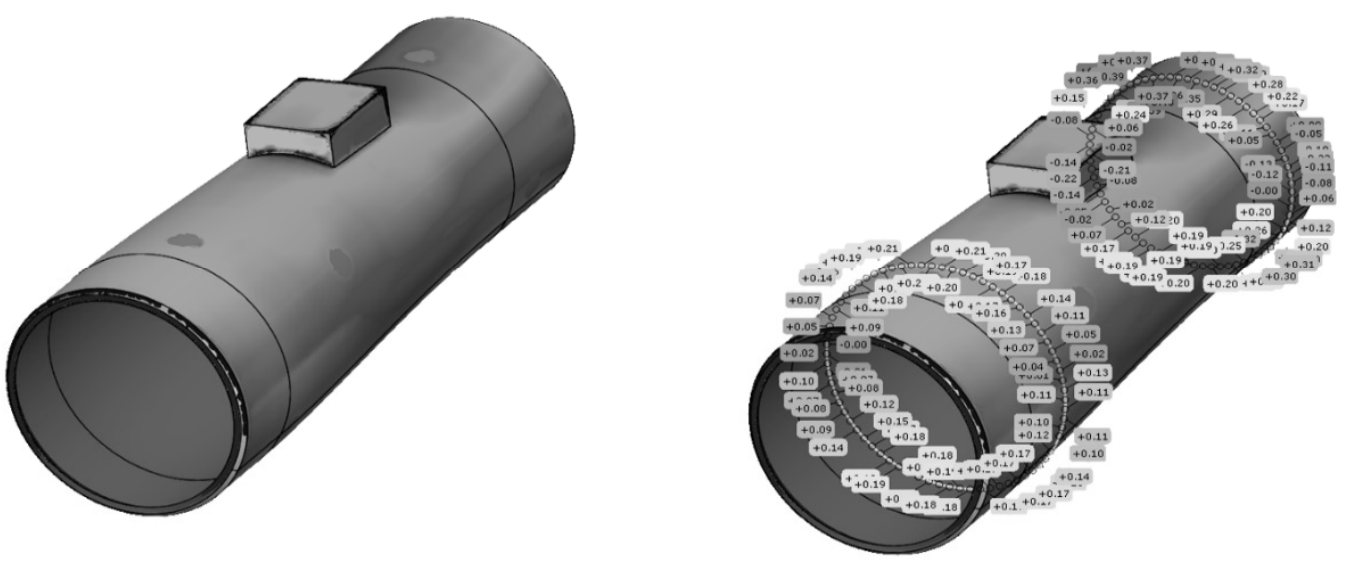

Fig. 13 Difference report carbon fiber tube with $C A D$ model

\section{Results}

In the following chapter, the results are analysed and discussed.

\subsection{Mold}

Only a small sample of measured points is recorded in table 2. Fig. shows the chosen coordinate system in terms of the angle value of the points in each cross-section. Points with $\pm 90^{\circ}$ angle were excluded from the sample because of the chamfer on the edge of the mold. The arithmetic mean cross-section is calculated from all measured cross-sections, not only the ones recorded in table 2.

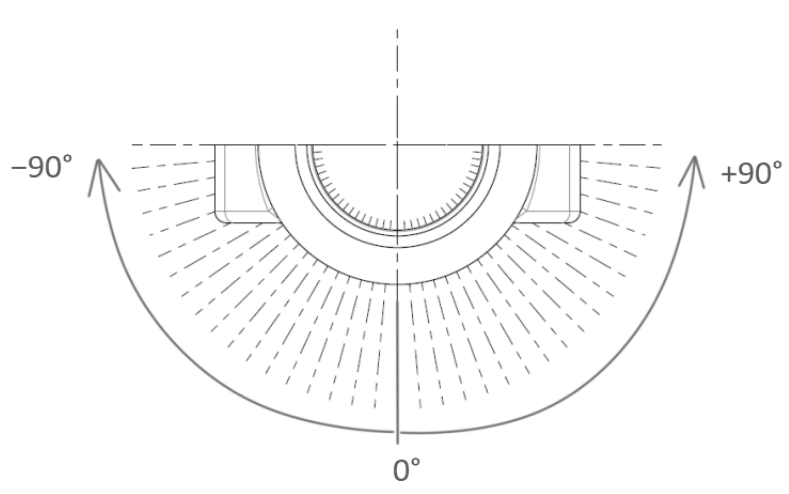

Fig. 14 Dimensioning of measured points on the mold

Tab. 2 Deviations of points of the mold

\begin{tabular}{|c|c|c|c|c|c|c|}
\hline \multirow[b]{2}{*}{ Angle $\left[{ }^{\circ}\right]$} & \multicolumn{6}{|c|}{ Deviation [ $\mathrm{mm}$ ] for various cross-section } \\
\hline & $25 \mathrm{~mm}$ & $65 \mathrm{~mm}$ & $95 \mathrm{~mm}$ & $125 \mathrm{~mm}$ & $155 \mathrm{~mm}$ & $\begin{array}{l}\text { Arithmetic mean } \\
\text { cross-section }\end{array}$ \\
\hline-85 & -0.20 & -0.31 & -0.28 & -0.31 & -0.38 & -0.294 \\
\hline-80 & -0.16 & -0.27 & -0.21 & -0.26 & -0.33 & -0.246 \\
\hline-75 & -0.15 & -0.21 & -0.15 & -0.20 & -0.28 & -0.198 \\
\hline-70 & -0.13 & -0.18 & -0.10 & -0.14 & -0.24 & -0.162 \\
\hline-65 & -0.09 & -0.15 & -0.05 & -0.10 & -0.23 & -0.130 \\
\hline $\begin{array}{l}. \\
. \\
.\end{array}$ & $\begin{array}{l}. \\
. \\
.\end{array}$ & . & $\begin{array}{l}\cdot \\
. \\
.\end{array}$ & $\begin{array}{l}. \\
. \\
.\end{array}$ & $\begin{array}{l}\cdot \\
. \\
.\end{array}$ & . \\
\hline 55 & -0.02 & -0.07 & -0.09 & -0.03 & -0.12 & -0.076 \\
\hline 60 & -0.06 & -0.11 & -0.12 & -0.10 & -0.20 & -0.124 \\
\hline 65 & -0.07 & -0.16 & -0.16 & -0.19 & -0.31 & -0.178 \\
\hline 70 & -0.10 & -0.20 & -0.20 & -0.26 & -0.39 & -0.226 \\
\hline 75 & -0.13 & -0.22 & -0.26 & -0.31 & -0.47 & -0.269 \\
\hline 80 & -0.15 & -0.25 & -0.31 & -0.39 & -0.55 & -0.317 \\
\hline 85 & -0.20 & -0.28 & -0.37 & -0.43 & -0.62 & -0.370 \\
\hline
\end{tabular}


Fig. 15 plots values of deviations from table 2 . Large deviations for values above $\pm 50^{\circ}$ can be observed. It suggests significant warpage of the mold in the area near the parting line. The mold had tendency to close in on itself. Because the $3 \mathrm{D}$ scanning was carried out after manufacturing 10 CFRP parts in the mold, it is not clear whether the warpage happened directly after $3 \mathrm{D}$ printing or was a result of heat cycles in the autoclave.

The warpage of "C-shaped" parts is common due to stress distribution in these parts. As a result, measured cylindricity on the wider end of the mold (Fig. 11) is $0.24 \mathrm{~mm}$.

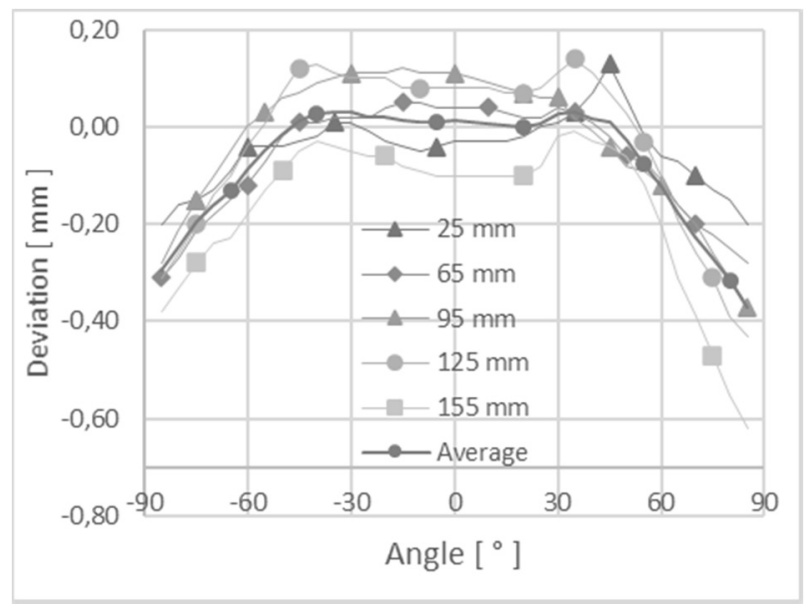

Fig. 15 Deviation of measured points in different sections
As can be observed on the "Average crosssection" - values the cavity is on average smaller than the nominal value from CAD data ( 0 on the y-axis in the plot). This is due to volume compensation of the shape of the mold. which was carried out based on the autoclave heat cycle (Fig. 6).

\subsection{Tube}

The tube was measured in a similar way to the mold (Fig. 16) - sample data of data is recorded in table 3 .

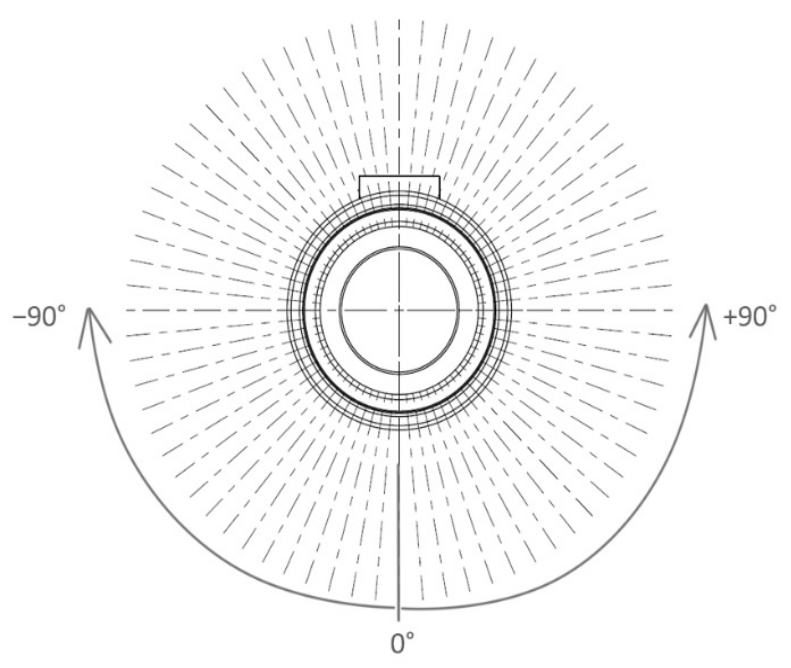

Fig. 16 Dimensioning of measured points on the tube

Tab. 3 Deviations of points of the tube

\begin{tabular}{|c|c|c|c|c|c|c|}
\hline \multirow[b]{2}{*}{ Angle $\left[{ }^{\circ}\right]$} & \multicolumn{6}{|c|}{ Deviation [ $\mathrm{mm}]$ for various cross-section } \\
\hline & $35 \mathrm{~mm}$ & $65 \mathrm{~mm}$ & $95 \mathrm{~mm}$ & $125 \mathrm{~mm}$ & $145 \mathrm{~mm}$ & $\begin{array}{l}\text { Arithmetic mean } \\
\text { cross-section }\end{array}$ \\
\hline-85 & 0.07 & -0.01 & 0.04 & -0.04 & -0.19 & 0.000 \\
\hline-80 & 0.08 & 0.03 & 0.11 & 0.02 & -0.14 & 0.038 \\
\hline-75 & 0.08 & 0.07 & 0.16 & 0.08 & -0.08 & 0.071 \\
\hline-70 & 0.09 & 0.10 & 0.2 & 0.12 & -0.05 & 0.095 \\
\hline-65 & 0.12 & 0.12 & 0.25 & 0.16 & -0.02 & 0.130 \\
\hline . & $\begin{array}{l}. \\
. \\
.\end{array}$ & $\begin{array}{l}. \\
. \\
.\end{array}$ & $\begin{array}{l}\text {. } \\
\text {. }\end{array}$ & $\begin{array}{l}. \\
. \\
.\end{array}$ & . & $\begin{array}{l}. \\
. \\
.\end{array}$ \\
\hline 55 & 0.11 & 0.08 & 0.10 & 0.25 & 0.26 & 0.154 \\
\hline 60 & 0.10 & 0.07 & 0.06 & 0.21 & 0.20 & 0.127 \\
\hline 65 & 0.10 & 0.05 & 0.02 & 0.16 & 0.12 & 0.087 \\
\hline 70 & 0.10 & 0.04 & -0.02 & 0.10 & 0.06 & 0.056 \\
\hline 75 & 0.11 & 0.02 & -0.07 & 0.05 & 0.00 & 0.032 \\
\hline 80 & 0.11 & -0.02 & -0.06 & 0.00 & -0.08 & 0.006 \\
\hline 85 & 0.11 & -0.04 & 0.00 & -0.01 & -0.12 & 0.002 \\
\hline
\end{tabular}

In Fig. 17, data from table 2 are plotted. As expected, the shape of the lines closely resembles the surface of the mold. This result suggests, that the quality of the tube would be highly improved if metal machined mold had been used. Direct comparison of average cross-sections of the 3D printed prototype mold and the tube is shown in Fig 18. Dhaval and Patel present a comparison of part manufactured by infusion and prepreg lay-up in their paper [12]. In their case, the precision of the infused part was greater than the part made from prepregs.

There is not apparent spring-back of the part due to its tubular shape. Paper by Dhaval and Gajjar [13] deals with spring-back of "L-shaped" parts. 
As the plots show, the average cross-section of the tube has deviations consistently above the nominal value of the CAD data. This suggests, that the thermal compensation mentioned in Chapter 3 does not directly correspond with the real situation. The fact that the deviation of the tube is greater, than the deviation of the mold caused difficulty when removing the part from the mold.

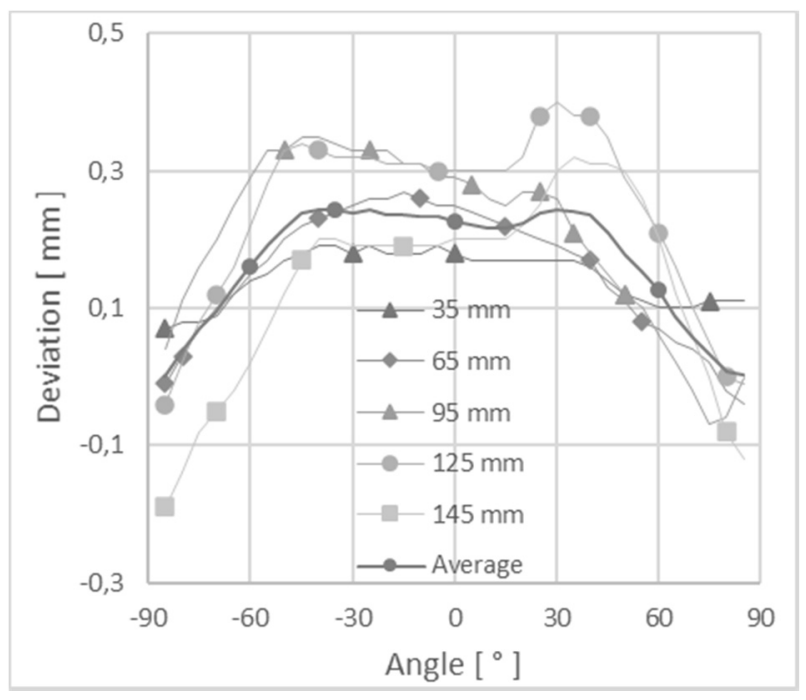

Fig. 17 Deviation of measured points in different sections

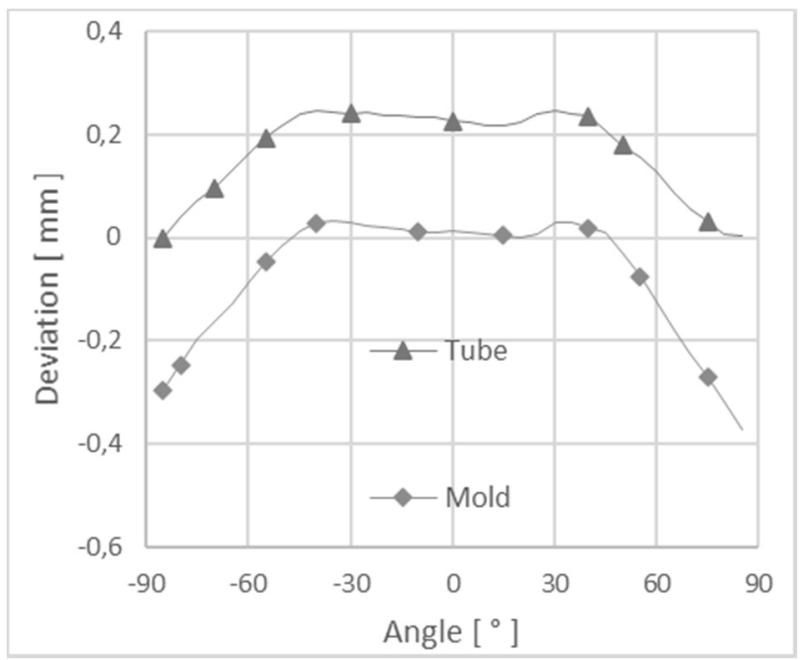

Fig. 18 Comparison of deviations of average cross-sections of the mold and tube

\section{The Following research}

More research needs to follow up in order to examine the use of CFRP in the field of sports optics in a comprehensive way.

Even more important than the initial precision of manufacturing is the thermal stability of the part itself and the bonds with other components. It is important that adhesive that is used can withstand climatic conditions at which binoculars are tested. Because of that temperature stability test of adhesive joints tests have been designed.

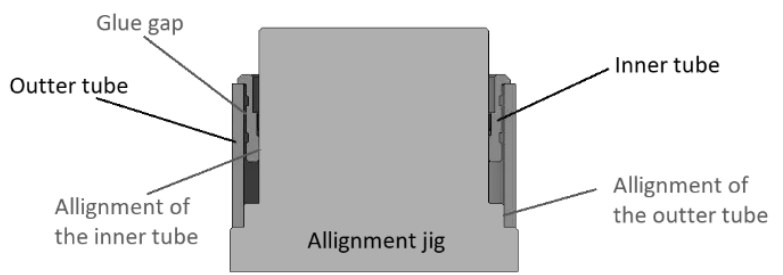

Fig. 19 Samples on the alignment jig

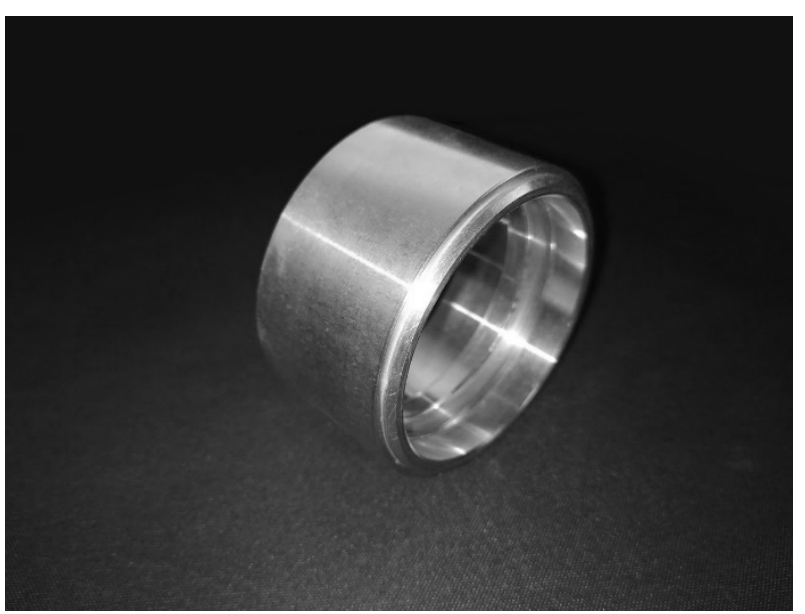

Fig. 20 Adhesive test sample

Measured samples consist of two metal cylinders that are glued together on a jig to ensure concentricity Fig. 19 and Fig. 21. The gap that is filled with glue is 3 $\mathrm{mm}$ wide. Because of that, the long-term concentricity of the inner and outer tube is determined by the stability of the glue. In the future, various sizes of the gap will be tested. When the adhesive is fully cured concentricity of the tubes is measured on CMM Zeiss Contura G2 to get a reference Fig. 21.

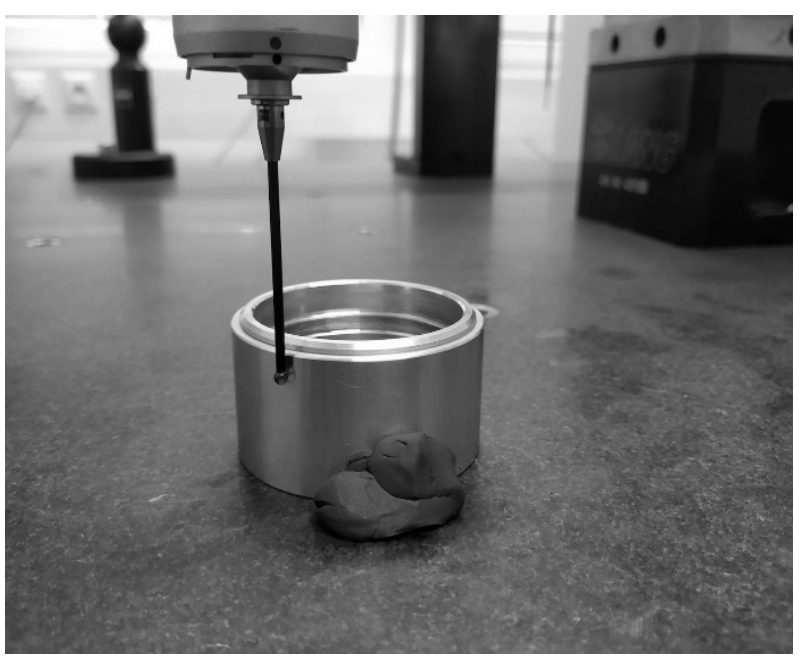

Fig. 21 Measurement of the adhesive test sample

Temperature tests follow. The samples will be placed in a climatic chamber (range of temperatures will be tested). Concentricity is measured after every test. The first set of tests has the samples standing on their faces. Tests in the horizontal position will follow to 
get results with different types of stress on the glue. The tests are still in progress and the results are not ready yet.

Careful choice of manufacturing technology for the tubular CFRP part would be another point of interest in future work. This problem needs to be tackled from multiple points of view. One of them is to examine which technology brings parts with the best mechanical properties regarding stiffness and strength. Kulhavý deals with this problematic in his papers, in his work he compares experiments with numerical simulations as well as compering different manufacturing technologies [14][15]. Another problem is the precision and stability of CFRP parts. There is not much research that has been made at this moment, the impact of manufacturing technology on precision and stability needs to be quantified by experiments made with a large sample of parts.

\section{Conclusion}

The main purpose of this paper was to design and manufacture a prototype sample using a CFRP manufacturing technology. It served as a proof of concept in terms of manufacturing a binoculars-like body using CFRP. The two-piece prototype mold and the CFRP tube were 3D scanned using optical 3D scanner GOM ATOS. The measured data were evaluated and compared to the nominal CAD model.

As expected, the precision of the mold strongly affects the final precision of the manufactured part. The two-piece negative prototype mold mentioned in this paper, which was made from polycarbonate, showed a warpage deformation and as a result, the tube part was narrower near the parting line. As expected, the topography of the surface of the final part closely resembles the topography of the surface of the mold.

The average deviation of the mold is negative meaning that the mold is smaller than expected. It is caused by relatively high coefficient of thermal expansion of polycarbonate. During the conditions in autoclave -6 bar and $120^{\circ} \mathrm{C}$ the tube expanded and after cooling to the room temperature shrinked. After curing the part was difficult to remove from the mold as a result of small cure shrinkage of the epoxy resin.

These imperfections are acceptable when considered the material and technology of the manufacturing of the mold. FDM is primarily an alternative technology for prototype production in the case of molds. Mentioned problems would be eliminated if machined metal mold had been used.

As mentioned in the chapter "The following research" the thermal stability of parts and joints may be more crucial, therefore it will be the focus of future tests.

\section{Acknowledgement}

This research work was supported by the Brno University of Technology, Faculty of Mechanical Engineering, Spe-cific research 2019, with the grant " Research of perspective production technologies ", FSI-S-19-6014.

\section{References}

[1] LOSCH, D.; EKANAYAKE, S.; NIENHEYSEN, P.; BETHLEHEMEICHLER, K.; SCHMITZ, R.; BIER, S.; ROSSMANN, J. (2017); An Industry 4.0-based repair concept for structural CFRP components in the automotive sector, 2nd IEEE International Symposium on Robotics and Manufacturing Automation, Roma, Article number 7847801

[2] COMPOTECH [4.11.2019], https://compotech.com/technology/composite-characteristics/, Composite characteristics, Compotech, 2019

[3] CAMPBELL, F. (2010) Structural composite materials. Materials Park, Ohio: ASM International. ISBN 16-150-3037-9.

[4] ŽMINDÁK, M.; PELAGIC, Z.; SOUKUP. (2015); Analysis of fiber orientation influence to dynamic properties of composite structures, Manufacturing Technology, Vol 15, p. 490-494

[5] CAMPBELL, F. C. (2004). Manufacturing processes for advanced composites. New York: Elsevier, 2004. ISBN 978-185-6174-152.

[6] HADAŠ, Z.; ZOUHAR, J.; SINGULE, V.; ONDRŮŠEK, Č. (2008) Design of Energy Harvesting Generator Base on Rapid Prototyping Parts. 13th Power Electronics and Motion Control Conference. 1. Poznan, POLAND: s. 16881692. ISBN: 978-1-4244-1741- 4

[7] STRATASYS [4.11.2019], https://www.stratasys.com/-/media/files/material-spec-sheets/mss_fdm_pc_1117a.pdf, PC (Polycarbonate) material spec sheet, STRATASYS, 2017

[8] DELTA PREG, [4.11.2019], http://www.tanso.se/wp-content/uploads/2017/03/CatalogA4_2017Feb.pdf, DeltaPreg Catalogue, Delta-Preg, 2017

[9] BÍLEK, O.; ŽALUDEK, M.; ČOP, J. (2016). Cutting tool performance in end milling of glass fiber-reinforced polymer composites, Мапufacturing Technology, Vol 16, p. 12-16

[10] ZOUHAR, J.; PÍŠA, Z.; SEDLÁK, J.; SEDLÁČEK, J. (2007) Productive machining with reverse engineerinng methods. In Frézování 
IV. Brno: FSI, BUT Brno, p. 189-196. ISBN: 80-214-3239- X

[11] SEDLÁK, J.; POLZER, A.; CHLADIL, J.; SLANÝ, M.; JAROŠ, A. (2017). Shape Inspection of Gear Prototypes Using Reverse Engineering Method. Manufacturing Technology, vol. 6, p. 945-952. ISSN: 1213-2489.

[12] DHAVAL, D; PATEL, L; PATEL, A; PARIZAL, ARVIND, I V. (2018). Experimental investigation on spring-back deformation during autoclave curing of parabolic antenna reflectors. Composites Part A: Applied Science and Manufacturing, Vol 115, p. 134-146
[13] GAJJAR, T; DHAVAL, D; JOSHI, S; PATEL, K. (2019). Experimental and simulation investigation on spring-in deformation for L-shape component. Curved and Layered Structures. Vol 6, , p. $169-180$

[14] KULHAVY, P; FLIEGEL, (2019). Experimental and Numerical Analysis of Dynamic Properties of Wound and Wrapped Carbon Composites. Manufacturing Technology Vol. 19, No. 2 ISSN 1213-2489

[15] KULHAVY, P; LEPŠíK, P, (2018). Design of Composite Structures Using Advanced Numerical Tools. Manufacturing Technology Structures. Vol. 18, No. 3, ISSN 1213-2489 